\title{
Fine-scale features on the sea surface in SAR satellite imagery - Part 1: Simultaneous in-situ measurements
}

\author{
A. Soloviev ${ }^{1}$, C. Maingot ${ }^{1}$, S. Matt ${ }^{1}$, R. E. Dodge ${ }^{1}$, S. Lehner ${ }^{2}$, D. Velotto ${ }^{2}$, \\ S. Brusch ${ }^{2}$, W. Perrie ${ }^{3}$, and E. Hochberg ${ }^{4}$ \\ ${ }^{1}$ Nova Southeastern University's Oceanographic Center, Dania Beach, USA \\ ${ }^{2}$ German Aerospace Center, Wessling, Germany \\ ${ }^{3}$ Bedford Institute of Oceanography, Dartmouth, Nova Scotia, Canada \\ ${ }^{4}$ Bermuda Institute of Ocean Sciences, St. George's, Bermuda \\ Received: 11 July 2012 - Accepted: 12 August 2012 - Published: 17 September 2012 \\ Correspondence to: A. Soloviev (soloviev@ nova.edu) \\ Published by Copernicus Publications on behalf of the European Geosciences Union.
}

\begin{abstract}
This work is aimed at identifying the origin of fine-scale features on the sea surface in synthetic aperture radar (SAR) imagery with the help of in-situ measurements as well as numerical models (presented in a companion paper). We are interested in natural 5 and artificial features starting from the horizontal scale of the upper ocean mixed layer, around $30-50 \mathrm{~m}$. These features are often associated with three-dimensional upper ocean dynamics. We have conducted a number of studies involving in-situ observations in the Straits of Florida during SAR satellite overpass. The data include examples of sharp frontal interfaces, wakes of surface ships, internal wave signatures, as well as 10 slicks of artificial and natural origin. Atmospheric processes, such as squall lines and rain cells, produced prominent signatures on the sea surface. This data has allowed us to test an approach for distinguishing between natural and artificial features and atmospheric influences in SAR images that is based on a co-polarized phase difference filter.
\end{abstract}

\section{Introduction}

Fine horizontal features on scales less than the typical scale of the upper ocean mixed layer depth (1-100 $\mathrm{m}$ ) are often associated with three dimensional processes (Soloviev and Lukas, 2006). The new generation of SAR satellites (TerraSAR-X, RADARSAT 2, ALOS PALSAR, CosmoSky Med) provides high-resolution images starting from meter

20 scale, also in dual or quad polarization. These technological achievements have made it possible to improve the interpretation of fine-scale features on the sea surface in SAR imagery and to identify the physical processes behind these features.

Satellite-based synthetic aperture radar (SAR) has the advantage of penetrating through clouds and is independent of the time of day. As this technology continues to advance, it produces better and higher resolution images of the ocean surface. Interpretation of these images is a complex problem including upper ocean dynamics, 
presence of surface active materials, wind-wave interactions, atmospheric influence, and parameters of the satellite antenna.

The fine-scale features observable in SAR include surface signatures of ship wakes, sharp frontal interfaces, freshwater plumes, and internal waves. The visibility of these

5 features can be enhanced or masked due to the presence of natural or anthropogenic surfactants. Atmospheric phenomena such as rain, atmospheric fronts and atmospheric internal waves can also leave signatures on the sea surface, complicating the interpretation of SAR images.

The visibility of oceanic fronts in SAR intensity images has been analysed in Bulatov 10 et al. (2003) and Johannessen et al. (2005). Surface signatures of internal waves were discovered on the images received from the first SAR satellite SEASAT launched by NASA in 1978 (Fu and Holt, 1982). Centreline wakes of ships are sometimes traced tens of miles behind the ship in SAR imagery (see e.g., Reed and Milgram, 2002; Soloviev et al., 2011; and others). Propagating freshwater plumes can also create fine 15 scale features on the sea surface visible in SAR images (Nash and Moum, 2005).

In the ocean application, satellite SAR responds to patterns of surface gravitycapillary waves in the range from a few centimetres to a few decimetres, depending on the selected band of electromagnetic wave frequency. The gravity-capillary waves can be affected by convergence-divergence zones on the sea surface due to internal 20 oceanic processes, by atmospheric processes (rain, wind gusts, coherent structures and stratification in the marine boundary layer) and by presence of surfactants or oil spills.

The role of surfactants in remote sensing of the sea surface with SAR has been extensively studied for several decades (see e.g., Alpers and Hühnerfuss, 1989; 25 Hühnerfuss et al., 1996; Gade et al., 1998; Ermakov et al., 2002; see also Gade et al., 2006 for an extensive review). In a study including numerical simulation and laboratory study, Soloviev et al. (2011) and Matt et al. (2011) have found the effect of suppression of turbulence below the sea surface resulting in an increase of temperature difference across the millimetre scale thermal molecular sublayer by a factor of 2 .

2887

This can affect high-resolution sea surface imagery in infrared (IR) and provide a link between SAR and IR features, since surfactants appear to modify both gravity capillary (Bragg scatter) waves and near surface turbulence.

The combination of numerical model, based on computational fluid dynamics, with a

5 radar imaging algorithm results in an effective approach for linking fine scale structures such as ship wakes, internal wave solitons, spreading freshwater lenses, sharp frontal interfaces with their SAR signatures (Fujimura et al., 2012; Matt et al., 2012). This work is aimed at utilizing these technological and computational advances in order to improve our ability to identify small-scale processes in the upper layer of the ocean from 10 high-resolution SAR satellites. In Part 1 of this work, we have conducted a number of experiments including in-situ observations and release of surfactants in the Straits of Florida during SAR satellite overpasses.

The paper is structured as follows. In Sect. 2, we describe experiments conducted in the Straits of Florida in 2009-2011 during SAR satellite overpasses. Section 3 anal15 yses results of experiments and provides examples of the oceanic processes that can have fine-scale signatures in SAR imagery. Influence of atmospheric process on SAR imagery of the sea surface is discussed in Sect. 4 . Section 5 is devoted to the problem of distinguishing between natural and artificial fine scale features in SAR imagery of the sea surface. In this section, we test a co-polarized phase difference filter that

20 takes advantage of dual or quad polarized SAR data. Discussion of the results and conclusions are provided in Sect. 6.

\section{Experiments in the Straits of Florida}

We conducted a series of field experiments in 2009-2011 to collect in-situ measurements in the Straits of Florida off Port Everglades (Fig. 1). The in-situ measurements 25 were coordinated with satellite overpasses. Satellite images were acquired from the TerraSAR-X, RADARSAT-2, ALOS PALSAR, and COSMO SkyMed satellites. In-situ data was collected simultaneously with satellite overpasses and using an array of 
sensors. These sensors included a vessel-mounted sonar and CTD system to record near-surface data on stratification and frontal interfaces (Fig. 2), a bottom-mounted Nortek AWAC system to gather information on waves and currents, an ADCP mooring at a $240 \mathrm{~m}$ isobath, as well as a SeaKeeper SK1000 unit to record meteorological con-

5 ditions (Maingot, 2011). The parameters of ships in the satellite footprint were found through the use of the Automated Identification System (AIS). These data were then supplemented by photo images and video records of the sea surface taken from the boat and information from a nearby NOAA NEXRAD Doppler radar station, which provided current conditions and a history of rain fall in the area. Since it is known that,

10 under low wind speed conditions, surface active materials can affect the visibility of sea surface features in SAR imagery, controlled releases of menhaden fish oil were performed from our vessel before several satellite overpasses. The creation of artificial slicks, using fish oil, was conducted in the Straits of Florida on the Ft. Lauderdale shelf under a US Environmental Protection Agency permit. The experimental range 15 was located outside of the 3 mile zone.

\section{Observations}

\subsection{Slicks}

Figure 3 demonstrates results of an experiment during very low wind speed conditions. The SAR image suggests that the ocean surface in the core of the Gulf Stream is 20 practically smooth. The coastal area on the western flank of the Gulf Stream is, however, intermittently covered by ripples. This coastal area includes elongated slick lanes, which are predominately directed along the coast line. The nature of these slick areas is not completely clear. One possibility is that it was due to a difference in the sea surface temperature between the Gulf Stream and coastal water. During this experiment

25 in July, the sea surface temperature in the coastal waters near Ft. Lauderdale FL was

2889

higher than in the Gulf Stream. This could result in the convection motions above the coastal waters inducing short gravity-capillary waves on the sea surface.

A second possibility is that because this experiment was coincidently conducted during the Deepwater Horizon oil spill in the Gulf of Mexico, the oil spill products contain-

5 ing surface active materials (e.g. dispersants) could be transported by the Gulf Stream through the Straits of Florida during this time.

The elongated slick areas in the coastal waters could be caused by internal waves generated due to bottom topography or by the freshwater plume discharging from the Port Everglades channel. The latter mechanism has been conceptually modelled in the 10 companion paper (Matt et al., 2012).

\subsection{Gulf stream front}

The sonar transect and vertical temperature profile taken just after the satellite overpass time are shown in Fig. 4. The sonar transect was conducted by profiling the water column. The vessel was moving in an approximate east to west direction from point $A$ 15 to point $B$ on the map. This is also indicated in the sonar plot from A to B.

During this transect a frontal feature was observed with sonar, which approached the surface in approximately the same area as there was the front observed in the SAR image. Vertical temperature profiles conducted inshore of this area confirmed the presence of thermal stratification in the upper ocean layers.

\section{$20 \quad 3.3$ Internal wave signature}

Internal waves can have signatures in SAR imagery (Alpers, 1985). Figure 5 demonstrates a SAR image, which reveals a wave-like pattern, observed during our experiments in the Straits of Florida. This pattern is presumably due to internal waves developing on the thermocline. Note that atmospheric internal waves or atmospheric boundary-layer rolls can also produce a wave like pattern in SAR image. 
The R/V Panacea transect with sonar is shown in Fig. 5 by a pink line. This transect, however, finished before the vessel entered in the wave like pattern observed in SAR. As a result, we do not have direct in-situ confirmation that the wave-like pattern observed in this SAR image was produced by oceanic internal waves. However, the

5 structure of the wave-like pattern is consistent with oceanic internal waves (Alpers and Huang, 2011).

Note that large-amplitude internal wave solitons is an observable feature in the area of our experiments. Figure 6 demonstrates such an example obtained on 16 January 2011.

\section{$10 \quad 3.4$ Wakes of ships}

Figure $7 a$ demonstrates an example of the SAR image containing signature of two wakes from ships. The centreline wakes produced by these ships are clearly seen on the image. These ships have also been identified with AIS (Fig. 7b). Note an asymmetry of these wakes relative to wind direction. The upwind side of these wakes is bright,

15 while the downwind side is dark. This is consistent with previous observations in SAR (Lyden et al., 1988; Wahl et al., 1992) and photo (Gilman et al. 2011) images. This effect has been numerically reproduced by Fujimura et al. (2010, 2012). This type of asymmetry of the centreline ship wake in SAR imagery is explained by the hydrodynamic modulation of short surface waves due to convergence-divergence zones developing 20 in the wake.

The centreline ship wake in the presence of stratification in the near-surface layer of the ocean may also produce a thermal signature on the sea surface. In the example shown in Fig. 8, the R/V Panacea crossed the wake of a big ship three times. The centreline wake is well seen on the sonar contour plot. The sonar data also reveal a

25 shallow thermocline. The temperature data taken at $1 \mathrm{~m}$ depth from the R/V Panacea show negative anomalies associated with the first and second intersections of the wake but not with the third one. According to the sonar record, during the first and second intersections, the centreline wake penetrated the shallow thermocline, which resulted 2891

in bringing colder water to the surface. During the third intersection, the wake was weaker and could not reach the depth of thermocline; as a result, there was no specific thermal signature in the temperature record. Interaction of ship wake with a shallow thermocline has been conceptually reproduced in the companion paper (Matt et al., 5 2012).

\section{Influence of atmospheric processes}

Short gravity capillary waves on the sea surface are primarily generated by wind stress and can be modulated by oceanic and atmospheric processes. A series of SAR images taken under different wind speed conditions during our experiments suggests that with 10 increasing wind speed, the visibility of signatures of natural fine-scale features in SAR (often associated with the presence of surface active materials) decreases, while artificial signatures, such as ship wakes or oil releases, are still detectable even under moderate wind speed conditions (Fig. 9).

Figure 10 demonstrates a strong rain signature in the polarimetric SAR image. The 15 area of rain is identifiable in the weather radar map and is consistent with a pronounced feature in SAR. The effect is due to gravity capillary waves generated by the impact of rain droplets on the sea surface.

As already mentioned in Sect. 3.3, atmospheric internal waves and atmospheric boundary-layer rolls can produce signatures in SAR. These signatures may look alike 20 to the signatures produced by the oceanic internal waves. Alpers and Huang (2011) have provided guidance on distinguishing between atmospheric and oceanic wave-like signatures in SAR, which has been implemented for the interpretation of our observations in the Straits of Florida. 


\section{An approach to distinguishing among natural and artificial features and atmospheric influences}

Extensive imagery from observations of natural and man-made oceanic phenomena has been presented in Fu and Holt (1982), SAR Marine User's Manual (2004), Alpers

5 et al. (1999). However, it is often difficult to distinguish between the signatures of natural (slicks, atmospheric fronts, rain cells) and man-made (ship wakes, oil spills) phenomena.

Recently, Migliaccio et al. (2009) and Velotto et al. (2010) proposed a new approach to distinguish between oil spills and look-alikes in SAR images of the ocean surface.

10 This approach is based on the analysis of the co-polarized phase difference (CPD), defined as phase difference between complex $\mathrm{HH}$ and VV channels.

The CPD filter was originally developed for distinguishing oil spills from their lookalikes in SAR images. Mineral oil spills damp the short resonant Bragg waves, which results in a high random scattering mechanism and as a consequence, in a low HH-VV

15 correlation (Nunziata et al., 2011). In contrast, a natural surfactant monolayer covering the sea surface produces relatively weak damping. The HH-VV correlation in the case of a surfactant monolayer is relatively high and almost the same as for the clean surface (Migliaccio et al., 2009). Consequently, the phase difference between $\mathrm{HH}$ and VV channels allows distinguishing between areas covered by mineral oil spills and a broad

20 class of look-alikes, which are characterized by weaker damping properties. This result has been implemented by Migliaccio et al. (2009) and Velotto et al. (2012) in the form of the co-polarized phase difference (CPD) filter, which is based on the phase difference between the complex $\mathrm{HH}$ and VV channels.

The basic ideas pursued in this approach were investigated in the Ph.D. theses of

25 F. Feindt (University of Hamburg, 1985) and M. Gade (University of Hamburg, 1996). Gade (1996) carried out very detailed studies using data of airborne and spaceborne radar sensors working in different bands. Gade inferred very complex conclusions from his data sets. At different bands and in the presence of different crude oil species,

2893

different artificial sea slicks and different biogenic slicks, dramatic differences between the polarization ratios were observed. However, the technology of the nineties of the last century did not allow conclusions that were on a sufficiently reliable statistical base. Obvious "tendencies" were observed; however, higher resolutions had been necessary 5 to form a solid base for Gade's "tentative conclusions".

We have applied the CPD filter to SAR images of artificial fish oil slicks, natural slicks, ship wakes, an atmospheric frontal line, and rain signatures collected in the Straits of Florida.

Figure 11 shows a SAR image taken during a fish oil release experiment in the 10 Straits of Florida. Environmental conditions during this experiment are given in Table 1. Besides two artificial slicks created by the release of fish oil, this image also contains signature of several ship wakes, atmospheric front, and natural slick of unknown origin. The results of processing the SAR image of the fish oil slicks with the CPD filter are shown in Fig. 12. After applying the CPD filter, the areas covered with fish oil appear 15 as bright features (Fig. 12).

The CPD filter has also been applied to the signature of a natural slick of unknown origin and a ship wake identified in Fig. 11. These features practically disappear from the image after applying the filter.

Figure 14 demonstrates another case from the Straits of Florida, which is charac20 terized by the presence of an atmospheric front and the signature of rain in the SAR image. The atmospheric front in the form of a squall line was identified from a photo taken during the experiment. The rain signature was identified from the NOAA composite reflectivity radar image. Similarly to the case of natural slick and ship wake, the atmospheric frontal signature disappears after applying the CPD filter. The rain cell

25 signature is, however, visible after processing with the CPD filter (Fig. 14). In contrast to the oil spill signature, the rain signature transforms into a dark feature.

Analysis of the cases presented in Figs. 11-14 suggests that the CPD filter is potentially an effective tool for distinguishing between the slicks produced by fish oil and other types of surface features. 


\section{Discussion and conclusions}

In this work, we have collected a large number of high-resolution SAR images, supported by in-situ observations. In certain cases, the in-situ data were helpful in the identification of the physical processes behind the sea surface signatures observed in

5 the SAR images. In particular, a sharp frontal interface on the western flank of the Gulf Stream was observed both in SAR and with sonar (Fig. 4). The frontal eddies and meanders identified in this SAR image were also seen on photo images of the sea surface taken during the satellite overpass (Fig. 3).

SAR responds to patterns of surface gravity-capillary waves. The gravity-capillary 10 waves can be affected by convergence-divergence zones on the sea surface due to internal oceanic processes. However, atmospheric processes (rain, wind gusts, coherent structures and stratification in the marine boundary layer) also produce signatures in SAR imagery of the sea surface. In particular, internal waves and rolls of atmospheric origin can produce wave-like patterns in SAR imagery. In addition, surface slicks of

15 natural and artificial origin further complicate interpretation of SAR images of the sea surface.

As a part of this work, we have explored the approach to distinguish between artificial slicks and natural features in SAR imagery of the ocean surface proposed in Migliaccio et al. (2009) and Velotto et al. (2010) based on earlier work of the University of

20 Hamburg group. We have tested this approach on the example of two high-resolution TerraSAR-X images collected during our experiments in the Straits of Florida. These images contained signatures of ship wakes, oceanic and atmospheric fronts, and natural slicks. During an overpass of TerraSAR-X, we created two artificial slicks using fish oil. During another overpass in the Straits of Florida, we observed a rain cell on the rain 25 radar signal and in SAR image. The CPD filter developed in Migliaccio et al. (2009) and Velotto et al. $(2010,2011,2012)$ has then been applied to the SAR images of fish oil slicks, natural slicks, ship wakes, atmospheric front and rain feature. After application of the CPD filter, the resulting SAR images of fish oil slicks appear as bright features,

2895

while the signatures of natural slicks, ship wakes and atmospheric front are much reduced. The rain signature is well seen after processing the image with the CPD filter. It, however, has opposite contrast compared to the oil spill and thus is clearly distinguishable from the oil spill.

SAR imagery potentially allows inferring the structure of other fields in the ocean. For example, SAR images of fine ocean features may be associated with thermal features (Perrie et al., 2010) as suggested by the examples of ocean eddies and meanders, a sharp frontal interface and ship wake shown in Figs. 3, 4 and 8, respectively. The SAR imagery may also be helpful in inferring magnetic fields produced in the upper ocean

10 by fine scale ocean processes such as internal wave solitons, sharp fronts, submesoscale eddies etc. (Vennerstrom et al., 2005). SAR signatures of ship wakes, freshwater plumes, and internal waves in association with thermal, salinity, and magnetic fields have been reproduced in the numerical process study combining hydrodynamic simulations with a radar imaging algorithm, which are presented in the companion pa15 per (Matt et al., 2012).

Results of this study suggest that under certain conditions the fine structure of the upper layer of the ocean can be inferred from high-resolution SAR imagery. Interpretation of SAR images is complicated by the presence of surfactants and signatures of atmospheric processes. In-situ measurements during SAR satellite overpasses and 20 numerical simulations are helpful for development of new techniques for interpretation of fine-scale radar signatures on the sea surface.

Acknowledgements. We thank Biao Zhang (BIO) and Jenny Fenton (NSU) for coordinating the acquisition of satellite imagery. Jon Wood (Ocean Data Technology Inc.) and Brian Ettinger (NSUOC) provided excellent field support. We acknowledge the Italian Space Agency, German

25 Aerospace Center, Canadian Space Agency, and Alaska Remote Sensing Facility for providing SAR satellite imagery during our experiments.

This work was supported by project "Hydrodynamics and Remote Sensing of Far Wakes of Ships" conducted at NSUOC, project "Characterization of Impact of Oceanographic Features on the Electromagnetic Fields in Coastal Waters" (ONR Award N00014-10-1-0938), and GoMRI 
project "Consortium for advanced research on transport of hydrocarbon in the environment" (PI: Tamay M. Özgökmen).

\section{References}

Alpers, W.: Theory of radar imaging of internal waves, Nature, 314, 245-247, 1985.

5 Alpers, W. and Hühnerfuss, H.: The damping of ocean waves by surface films: A new look at an old problem, J. Geophys. Res., 94, 6251-6265, 1989.

Alpers, W., Mitnik, L., Hock, L., and Chen, K. S.: The Tropical and Subtropical Ocean Viewed by ERS SAR, available at: www.ifm.zmaw.de/fileadmin/files/ers-sar (last access: September 2012), 1999.

10 Alpers, W. and Huang, W.: On the discrimination of radar signatures of atmospheric gravity waves and oceanic internal waves on synthetic aperture radar images of the sea surface, IEEE T. Geosci. Remote Sens., 49, 1114-1126, 2011.

Bulatov, M. G., Kravtsov, Yu. A., Lavrova, O. Yu., Litovchenko, K. Ts., Mityagina, M. I., Raev, M. D., Sabinin, K. D., Trokhimovskii, Yu. G., Tchuryumov, A. N., and Shugan, I. V.: Physical

15 mechanisms of aerospace radar imaging of the ocean, Physics-Uspekhi, 46, 63-80, 2003 (in Russian).

Ermakov, S. A., Sergievskaya, I. A., and Shchegolkov, Yu. B.: A Laboratory Study of Strong Modulation of Radar Signals due to Long Waves on the Water Surface Covered with a Surfactant Film, Radiophysics and Quantum Electronics, 45, 942-957, 2002.

$20 \mathrm{Fu}$, L. and Holt, B.: Seasat Views Oceans and Sea Ice With Synthetic Aperture Radar, JPL publication, 81-120, 1982.

Fujimura, A., Soloviev, A., and Kudryavtsev, V.: Numerical Simulation of the Wind-Stress Effect on SAR Imagery of Far Wakes of Ships, IEEE Geosci. Remote Sens. Lett., 7, 646-649, 2010.

25 Fujimura, A., Soloviev, A., Rhee, S. H., and Romeiser, R.: Coupled Model Simulation of Wind Stress Effect on Far Wakes of Ships in SAR Images, IEEE Tr. Geosci. Remote Sens., submitted, 2012.

Gade, M., Alpers, W., Huhnerfuss, H., Masuko, H., and Kobayashi, T.: Imaging of biogenic and anthropogenic ocean surface films by the multifrequency/multipolarization SIR-C/X-SAR, J. Geophys. Res., 103, 18851-18866, 1998.

Gade, M., Hühnerfuss, H., and Korenowski, G.: Marine Surface Films, Springer, 2006.

Gilman, M., Soloviev, A., and Graber, H.: Study of the Far Wake of a Large Ship, J. Atmos. Ocean. Tech., 28, 720-733, 2011.

Huhnerfuss, H., Alpers, W., Dannhauer, H., Gade, M., Lange, P. A., Neumann, V., and Wismann,

$5 \quad$ V.: Natural and man-made sea slicks in the North Sea investigated by a helicopter-borne 5frequency radar scatterometer, Int. J. Remote Sens., 17, 1567-1582, 1996.

Johannessen, J. A., Kudryavtsev, V., Akimov, D., Eldevik, T., Winther, N., and Chapron, B.: On radar imaging of current features: 2 . Mesoscale eddy and current front detection, J. Geophys. Res., 110, C07017, doi:10.1029/2004JC002802, 2005.

10 Maingot, C., Soloviev, A., Matt, S., Gilman, M., Fenton, J., Velotto, D., Brusch, S., and Lehner, S.: Sonar Measurements in the Gulf of Stream Front on the Southeast Florida Shelf Coordinated with TerraSAR-X Satellite Overpasses. In: Proceedings of the 17th AMS Conference on Air-Sea Interaction, 27-30 September 2010, Annapolis, MD, available at: http: //ams.confex.com/ams/pdfpapers/174803.pdf, 2010.

15 Lyden, J. D., Hammond, R. R., Lyzenga, D. R., and Schuchman, R. A.: Synthetic aperture radar imaging of surface ship wakes, J. Geophys. Res., 93, 12293-12303, 1988.

Nunziata, F., Migliaccio, M., and Gambardella, A.: Pedestal height for oil spill observation, IET Radar Sonar \& Navigation, 5, 103-110, doi:10.1049/iet-rsn.2010.0092, 2011.

Maingot, C.: Observation of Natural and Artificial Features on the Sea Surface from Synthetic Aperture Radar Satellite Imagery with In-situ Measurements, M.S. degree thesis, 88 pp., available from Nova Southeastern University Oceanographic Center, 2011.

Matt, S., Fujimura, A., Soloviev, A., and Rhee, S.: Modification of Turbulence Air-Sea Interface Due to the Presence of Surfactants and Implications for Gas Exchange. Part II: Numerical Simulations, in: Gas Transfer at Water Surfaces, Kyoto University Press, 299-312, 2011.

25 Matt, S., Fujimura, A., Soloviev, A., Rhee, S. H., and Romeiser, R.: Fine-scale features on the sea surface in SAR satellite imagery - Part 2: Numerical modeling, Ocean Sci. Discuss., 9, 2915-2950, doi:10.5194/osd-9-2915-2012, 2012.

Migliaccio, M., Nunziata, F., and Gambardella, A.: On the Copolarised Phase Difference for Oil Spill Observation, Int. J. Remote Sens., 30, 1587-1602, 2009.

30 Nash, J. D. and Moum, J. N.: River plumes as a source of large-amplitude internal waves in the coastal ocean, Nature 437, 400-403, 2005. 
Perrie, W., Xie, T., and Zhang, B.: SAR detection of ocean thermal front features. SEASAR 2010, ESA ESRIN, Frascati, Italy, available at: http://earth.eo.esa.int/workshops/seasar2010/ participants/515/pres_515_perrie.pdf, 25-29 January 2010.

Reed, A. M. and Milgram, J. H.: Ship wakes and their radar images, Annu. Rev. Fluid Mech., 34, 469-502, 2002.

Soloviev, A. and Lukas, R.: The Near-Surface Layer of the Ocan: Structure, Dynamcis, and Applicaitons, Springer, New York, 572 pp., 2006.

Soloviev, A., Gilman, M., Young, K., Brusch, S., and Lehner, S.: Sonar measurements in ship wakes simultaneous with TerraSAR-X overpasses, IEEE T. Geosci. Remote Sens., 48, 841851, 2010.

Soloviev, A., Matt, S., Gilman, M., Hühnerfuss, H., Haus, B., Jeong, D., Savelyev, I., and Donelan, M.: Modification of turbulence at the air-sea interface due to the presence of surfactants and implications for gas exchange. Part I: laboratory experiment, in: Gas Transfer at Water Surfaces, Kyoto University Press, 245-258, 2011.

15 Velotto, D., Migliaccio, M., Nunziata, F., and Lehner, S.: Oil-slick observation using single look complex TerraSAR-X dual-polarized data, IEEE International Geoscience and Remote Sensing Symposium (IGARSS), 3684-3687, 2010.

Velotto, D., Migliaccio, M., Nunziata, F., and Lehner, S.: Dual-Polarized TerraSAR-X Data for Oil-Spill Observation, Geoscience and Remote Sensing, IEEE Transactions, 49, 4751-4762, 2011.

Velotto, D., Lehner, S., Soloviev, A., and Maingot, C.: Analysis of Oceanic Features From DualPolarization High Resolution X-Band SAR Imagery For Oil Spill Detection Purposes, IEEE International Geoscience and Remote Sensing Symposium (IGARSS), Munich, Germany, 22-27 July 2012.

25 Vennerstrom, S., Friis-Christensen, E., Lühr, H., Moretto, T., Olsen, N., Manoj, C., Ritter, P., Rastätter, L., Kuvshinov, A., and Maus, S.: The Impact of Combined Magnetic and Electric Field Analysis and of Ocean Circulation Effects on Swarm Mission Performance. Swarm Science Studies, Final Report, Danish Space Research Institute, 138 pp., available at: http: //esamultimedia.esa.int/docs/EarthObservation/Swarm/External_Ocean_FR.pdf, 2005.

30 Wahl, T., Eldhuset, K., and Skøelv, Å.: Ship traffic monitoring using the ERS-1 SAR, in Proc. 1st ERS-1 Symp., Cannes, France, 823-828, 1992.

Table 1. Pertinent information to field experiment examples.

\begin{tabular}{lllllll}
\hline Figures & $\begin{array}{l}\text { Date, } \\
\text { Time }(\text { UTC) }\end{array}$ & $\begin{array}{l}\text { Wind } \\
\text { Speed }\left(\mathrm{m} \mathrm{s}^{-1}\right)\end{array}$ & $\begin{array}{l}\text { Wind } \\
\text { Direction }(\mathrm{deg})\end{array}$ & $\begin{array}{l}\text { Air } \\
\text { Temperature }\left({ }^{\circ} \mathrm{C}\right)\end{array}$ & $\begin{array}{l}\text { Water } \\
\text { Temperature }\left({ }^{\circ} \mathrm{C}\right)\end{array}$ & $\begin{array}{l}\text { Wave } \\
\text { Height }(\mathrm{m})\end{array}$ \\
\hline $11-13$ & 25 Sep 2009, 23:13 & $5.3^{1}$ & $81^{1}$ & $28.9^{1}$ & $30.2^{1}$ & $0.3^{2}$ \\
14 & 10 Jun 2010, 11:17 & $2.0^{3}$ & $335^{3}$ & $26.7^{3}$ & $29.2^{4}$ & $0.39^{5}$ \\
\hline
\end{tabular}

${ }^{1}$ Data from Fowey Rocks Station off the coast of Miami, FI $\left(25.590^{\circ} \mathrm{N}, 80.097^{\circ} \mathrm{W}\right)$.

2 Visual estimate.

${ }^{3}$ Meteorological Station at the Entrance to Port Everglades.

${ }^{4}$ Measured 50 min after overpass using CTD.

${ }^{5}$ Significant wave height measured with Nortek AWAC instrument. 


\section{Experimental Area \& In-Situ Measurements}
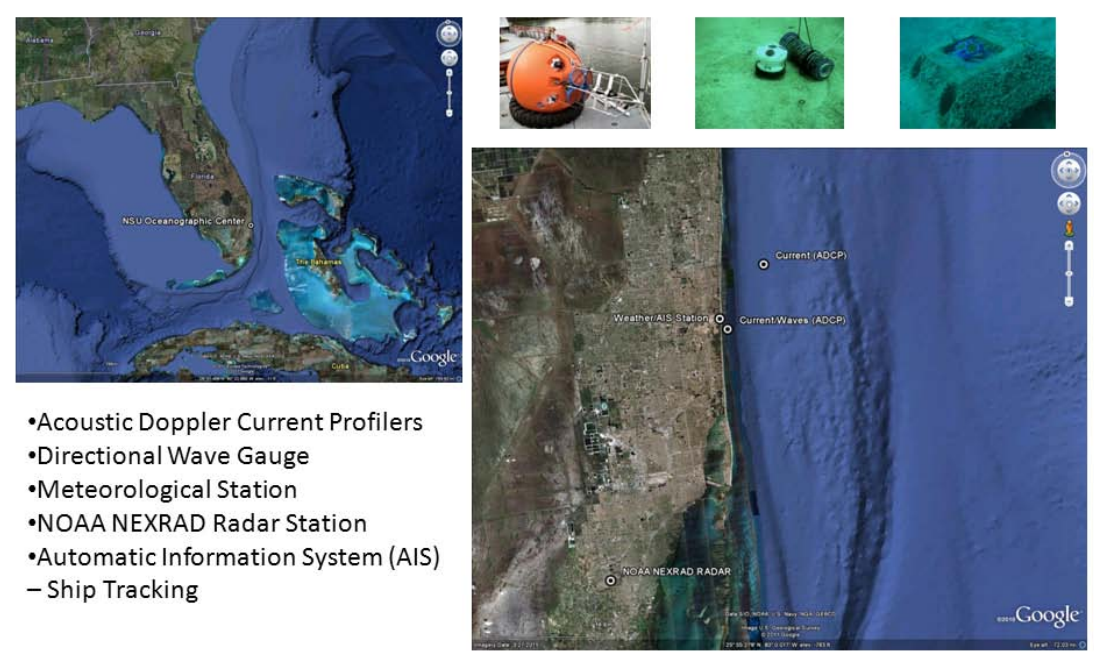

-Acoustic Doppler Current Profilers -Directional Wave Gauge

-Meteorological Station

-NOAA NEXRAD Radar Station

-Automatic Information System (AIS)

- Ship Tracking

Fig. 1. Map of observational area on the Southeast Florida shelf. Locations of measurements are denoted on the map. "Current/Waves" is the location of the Nortek AWAC instrument, whereas "Current (ADCP)" is the location of the sub-surface buoy outfitted with RDI ADCPs.

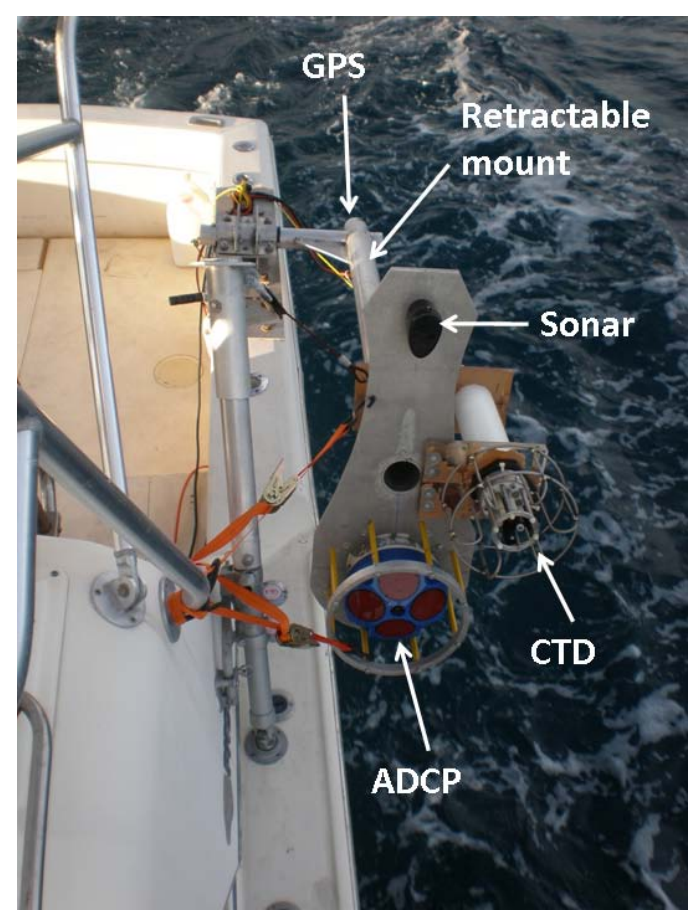

Fig. 2. Aluminium mount used to lower instruments over the side of the vessel. Mounting depth is approximately one meter. 

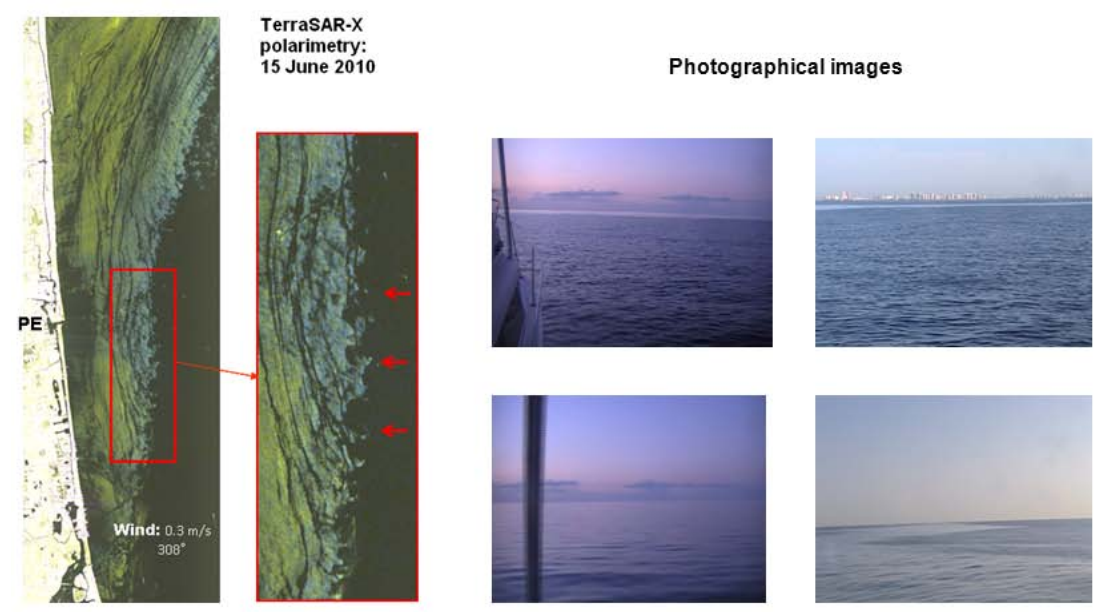

Fig. 3. The Gulf Stream front and expanded view demonstrating slick lines and submesoscale frontal eddies in TerraSAR-X imagery. These features were seen throughout the coastal area and were confirmed with the photos taken from the R/V Panacea before this satellite overpass.

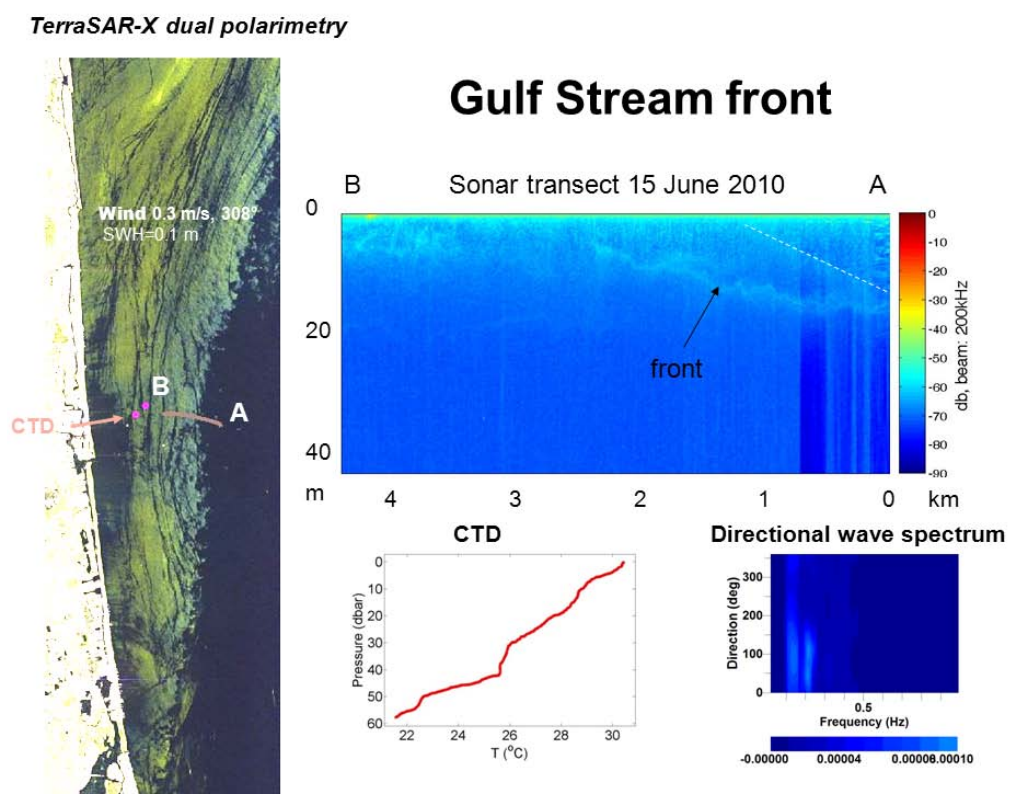

Fig. 4. (Left) TerraSAR-X image with location of CTD cast marked by red dot and trajectory of the research vessel for the horizontal transect marked by the pink line from A to B. A sharp front on the western flank of the Florida Current observed in the SAR image is presumably associated with an inclined front visible in the horizontal sonar transect. The dashed white line on the sonar contour plot is an acoustic artefact (late echo). The temperature profile measured from the CTD cast taken at a location on indicated by the red dot $\left(26^{\circ} 07.030^{\prime} \mathrm{N}, 80^{\circ} 04.154^{\prime} \mathrm{W}\right)$ and directional wave spectrum from the bottom mounted AWAC instrument are shown at the bottom of the figure. 


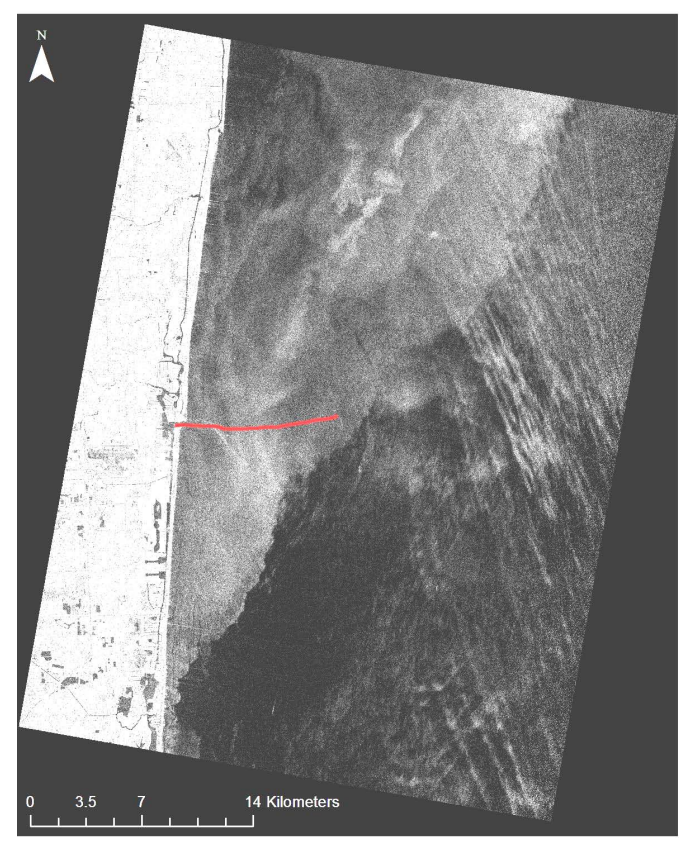

Fig. 5. SAR image of experimental domain (COSMO SkyMed Satellite, 1 September 2011). The red line indicates trajectory of the NSUOC boat taking in-situ measurements with ADCP, CTD, and sonar.

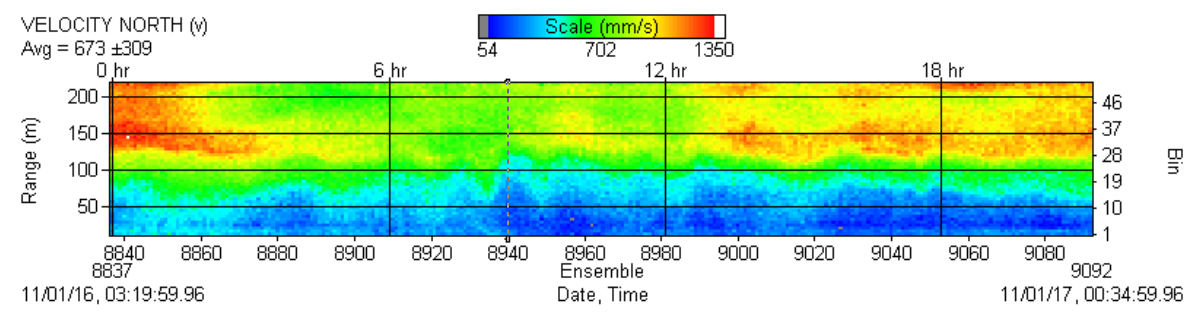

Fig. 6. An example of the internal wave soliton observed on 16 January 2011. The vertical coordinate on the contour plot is the height above the bottom. The soliton is found on the lower boundary of the thermocline. The internal wave period is about $1.5 \mathrm{~h}$, and its height reaches $75 \mathrm{~m}$. 

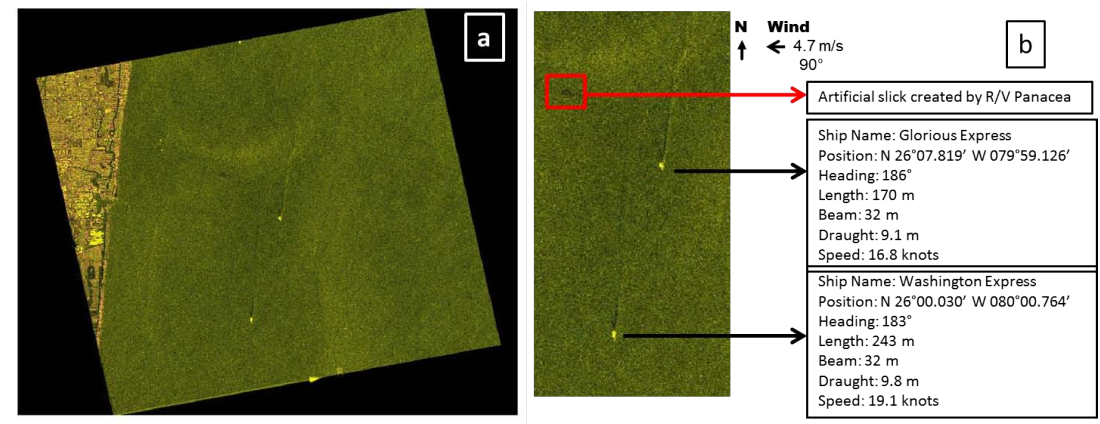

Fig. 7. (a) RADARSAT-2 image acquired 11 June 2010, 23:18 UTC. Image was acquired in quad polarization mode. Swath width of the image is $25 \mathrm{~km}$. (b) Enlarged view of the two ship wakes and the artificial slick seen in the centre of (a). AIS information about the ships collected at the time of the overpass is included.

\section{Sonar and Temperature Record During Wake Crossings}
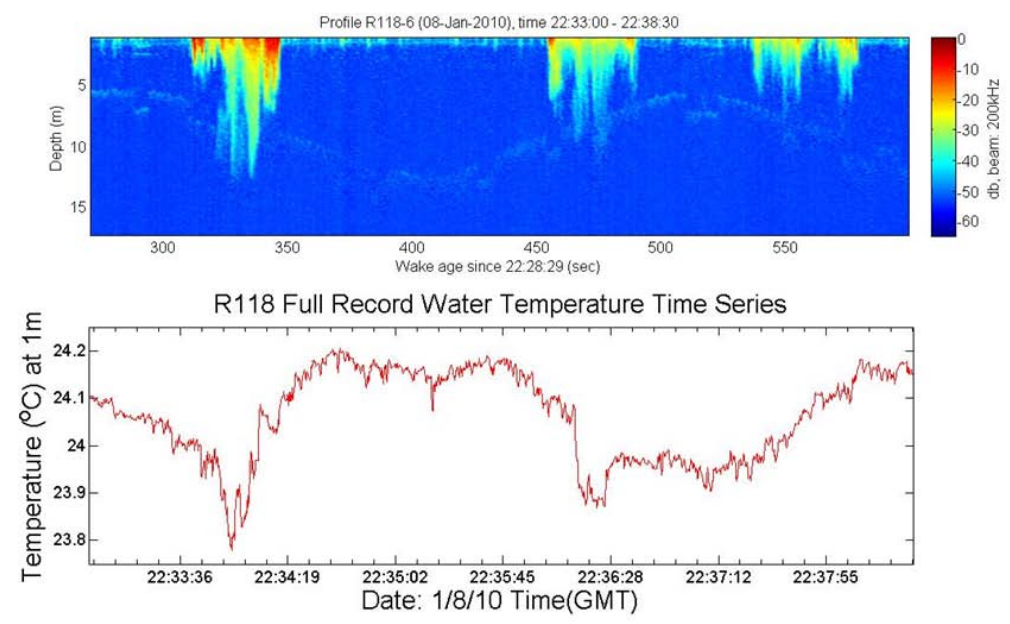

Fig. 8. Sonar and temperature record during ship wake crossing. Note a shallow thermocline also visible on the sonar record. 


\section{TerraSAR-X Polarimetric Imagery}

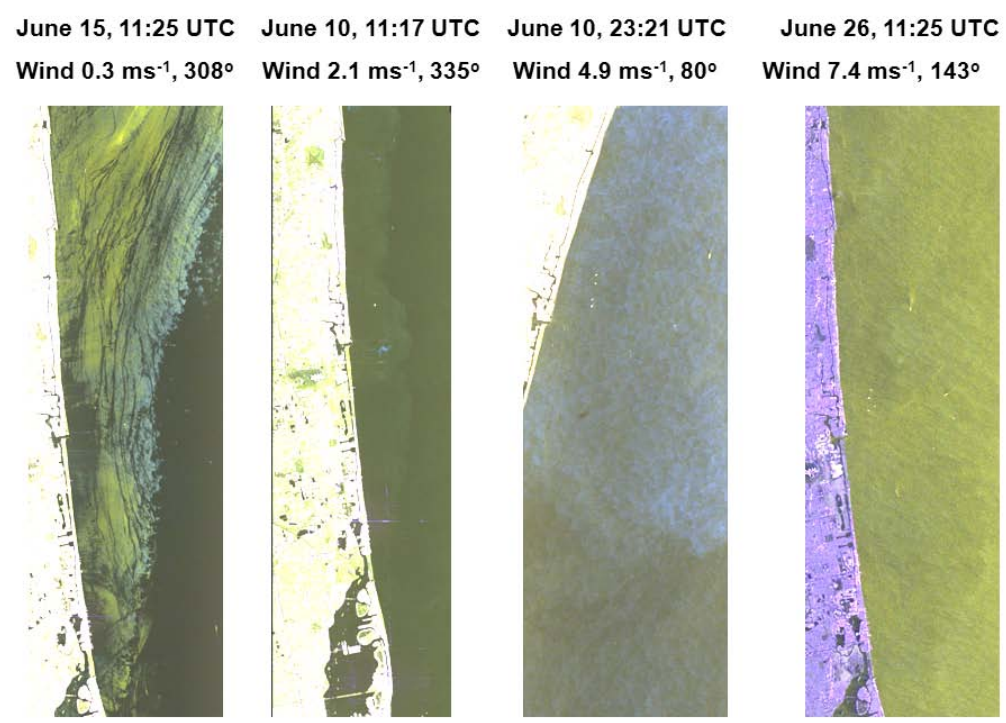

Fig. 9. TerraSAR-X polarimetric images. Natural slicks are prominent under very low wind speed conditions and disappear with increasing wind speed; while, artificial features can be seen even under moderate wind speed conditions.

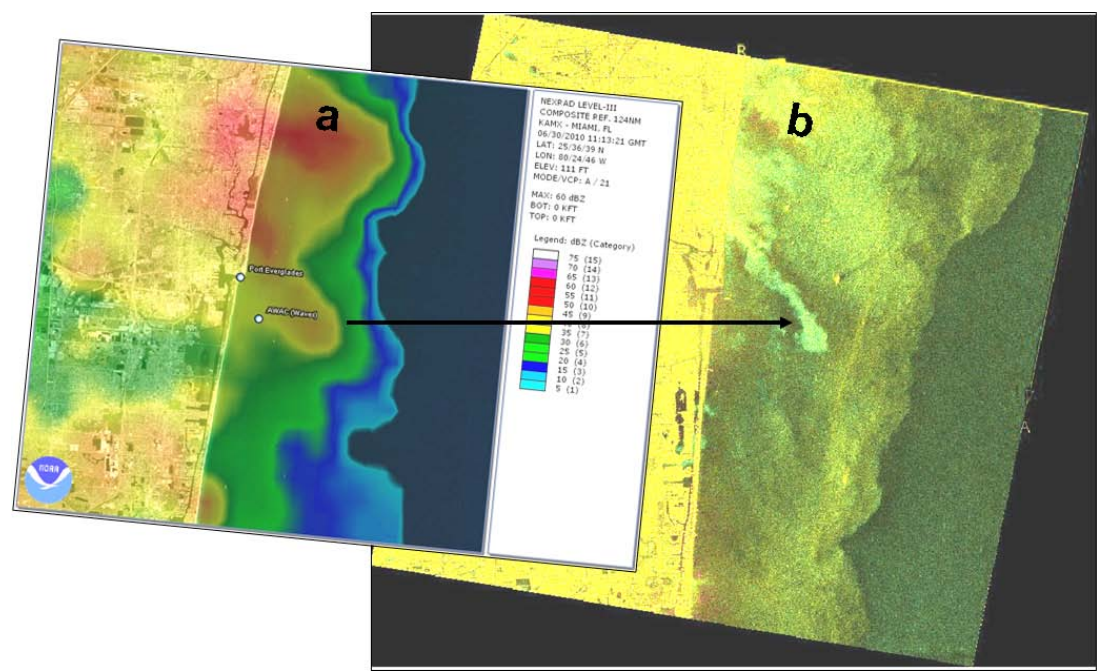

Fig. 10. (a) NOAA weather radar from the Miami, FL NEXRAD station on 30 June 2010, 11:13 UTC. The entrance to Port Everglades is indicated on the map for geographical reference. (b) RADARSAT-2 image acquired 30 June 2010, 11:14 UTC. Signatures of rain cells and atmospheric fronts are denoted on the image. 

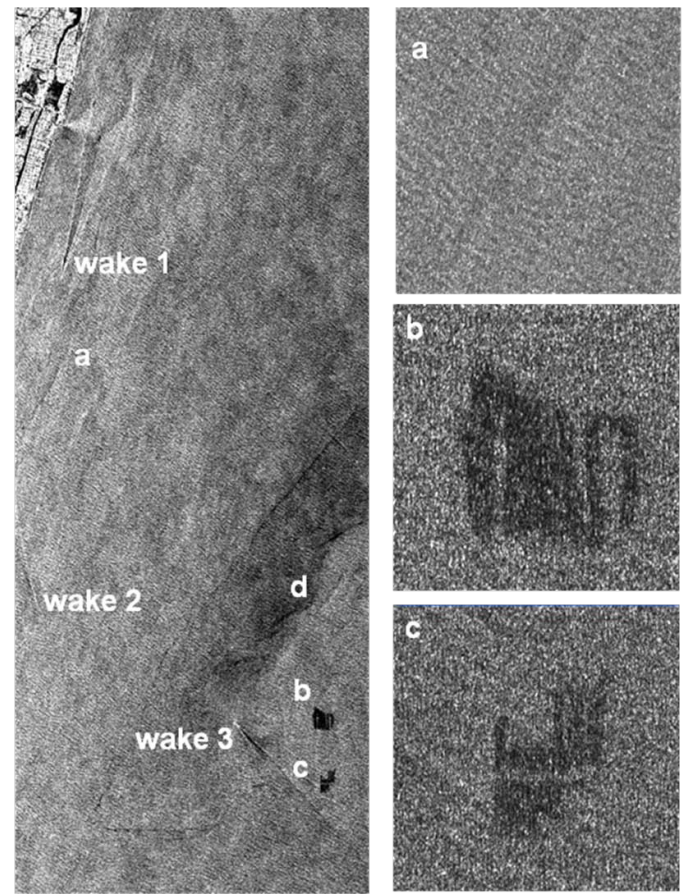

Fig. 11. A TerraSAR-X Stripmap image taken on 23:13 UTC 25 September 2009 (HH channel) off the coast of Ft. Lauderdale, Florida. The image reveals different features on the ocean surface: (a) oceanic front; (b) artificial slick, average age $80 \mathrm{~min}$; (c) artificial slick created with fish oil, average age $30 \mathrm{~min}$, a horizontal cut through the slick made by the passage of a boat is visible; (d) natural slick of unknown origin. Features $a, b$, and $c$ are shown in more details in the right column. A few wakes of ships are also visible (wake 1, 2, and 3 ).

2911

\section{Artificial oil spills}

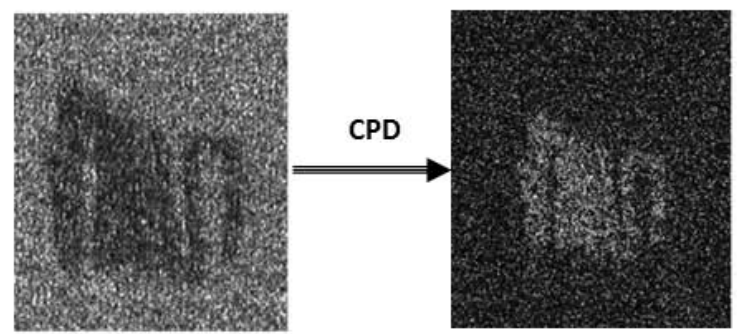

First fish oil release signature

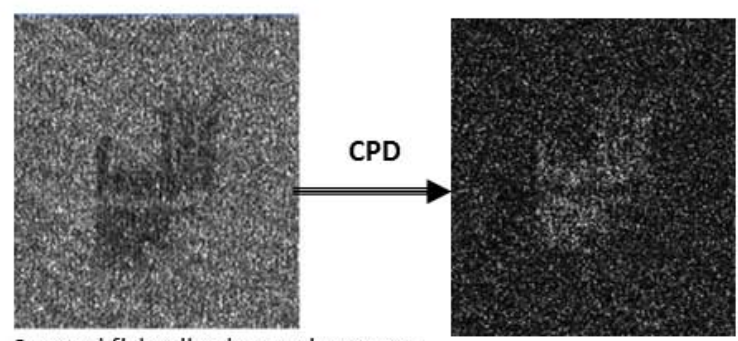

Second fish oil release signature

Fig. 12. Signature of a controlled oil spill releases in TerraSAR-X image and after applying the co-polarized phase difference (CPD): CPD standard deviation for a $3 \times 3$ window filter for the slicks made by the release of fish oil (see Fig. 11, feature "b" for the first fish oil release and "c" for the second fish oil release, respectively). 


\section{Natural Slick}

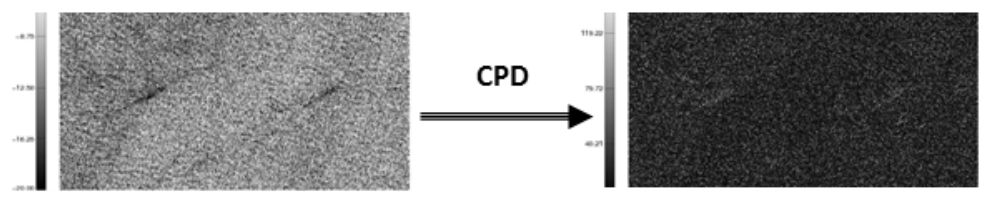

\section{Ship wake}

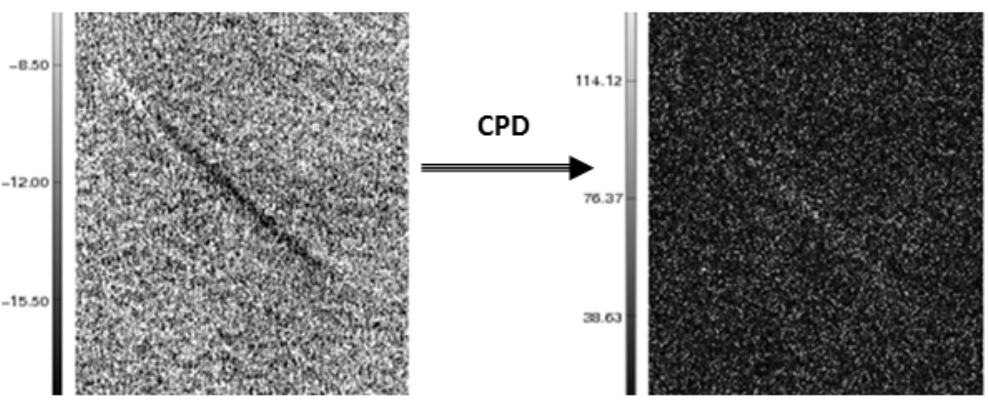

Fig. 13. Same as in Fig. 12 bot for natural slick (feature "d" in Fig. 11) and ship wake (feature "wake 3' in Fig. 11).

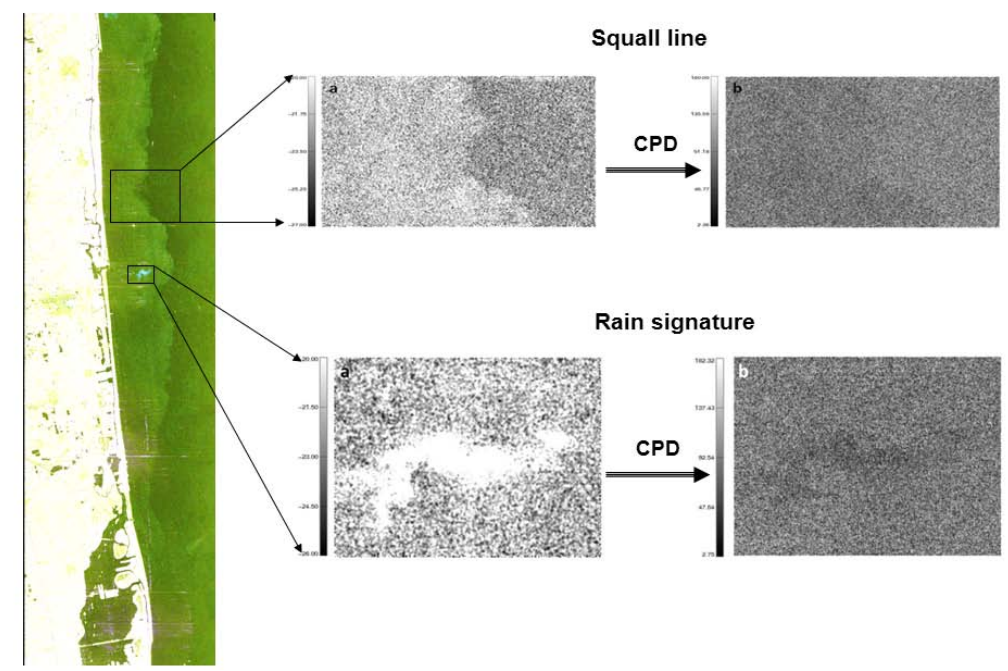

Fig. 14. Same as in Fig. 12 but for the atmospheric squall line and rain signature. The atmospheric squall line was also seen on a photo taken during this experiment; the rain feature was seen on the NEXRAD rain radar. 